\title{
Arte e interdisciplinaridade na Escola de Música da UEMG: uma análise da produção científica de alunos
}

Gisele Marino Costa

Mestre em Educação pela Faculdade de Educação da Universidade Federal de Minas Gerias (UFMG), especialista em Educação Musical e graduada em Música pela Escola de Música da UFMG.

\section{Maria Betânia Parizzi Fonseca}

Doutoranda em Desenvolvimento da Criança pela Faculdade de Medicina da Universidade Federal de Minas Gerias (UFMG), mestre em Educação Musical e graduada em Música pela Escola de Música da UFMG.

betaniaparizzi@hotmail.com

Thais Marques

Mestre em Música pela Escola de Música da Universidade Federal de Minas Gerais (UFMG), especialista em Educação Musical pela Escola de Música da UFMG e graduada em Música pela Escola de Música da Universidade Federal do Rio de Janeiro (UFRJ).

\section{Resumo}

O curso de licenciatura em educação artística com habilitação em música da Escola de Música da Universidade do Estado de Minas Gerais (ESMU/UEMG) formou em dezembro de 2007 sua última turma. A diversidade e a riqueza de temas escolhidos e desenvolvidos pelos alunos em suas monografias chamam a atenção para a relevância da interdisciplinaridade no ensino superior. A rica troca de ideias que norteou a elaboração dos projetos de pesquisa até seus resultados finais foi experiência relevante tanto para alunos e professores quanto para a instituição mantenedora do curso. $O$ interesse pelos temas dessas pesquisas vem demonstrar a heterogeneidade em educação como característica marcante da escola de hoje, bem como apontar para a pertinência da integração de currículos dos cursos superiores como ferramenta de aprofundamento de conhecimentos.

Palavras-chave: monografia; interdisciplinaridade; educação; licenciatura em música, educação artística. 


\section{Introdução}

O curso de licenciatura em educação artística com habilitação em música oferecido pela Escola de Música da Universidade do Estado de Minas Gerais (ESMU/UEMG) foi criado em 1983, com o objetivo de formar professores habilitados em educação musical e artística para atuarem em escolas de ensino fundamental e médio. Além disso, capacitava o aluno para atuar também em escolas livres de música, oficinas culturais, coros infantis, construção de instrumentos alternativos.

O currículo oferecia disciplinas relacionadas à música como, por exemplo, percepção musical, história da música, apreciação musical, instrumentos musicalizadores etc e outras relacionadas às linguagens artísticas tais como artes cênicas, fotografia, cinema e artes plásticas. A estrutura curricular apresentava ainda disciplinas de formação didático-pedagógica com conteúdos gerais e específicos de música. Suas diretrizes curriculares apontavam para a formação artística e musical do profissional, fundamentadas em saberes específicos e interdisciplinares'.

Anualmente o curso oferecia quarenta vagas. $O$ processo seletivo constava 38 de duas fases. Na primeira, eram avaliadas as habilidades musicais específicas. A prova era individual e verificava aspectos relativos à aptidão musical do candidato: afinação vocal, memória melódica e rítmica, coordenação motora, habilidade de criação musical. A segunda fase era o vestibular geral, com provas sobre os conteúdos exigidos no ensino médio.

O curso de licenciatura plena em educação artística com habilitação em música recebeu sua última turma em 2004, sendo extinto no ano seguinte, devido a fatores relacionados a mudanças na legislação educacional do país.

Para uma melhor compreensão desse contexto, recorremos às origens dos cursos de licenciatura em música no final da década de 1960. Pires (2003) relata que em 1969 o parecer 57 I/69 propõe a mudança do nome do curso de Professor de Educação Musical, então existente, para Licenciatura em Música, e define seus conteúdos e duração mínima. Mais tarde, a lei 5.692/7I cria as licenciaturas em educação artística com habilitações específicas, dentre as quais está presente a música. Segundo Pires (2003), a lei trata a educação artística como uma das linguagens para a comunicação e expressão na escola:

'Vide lista completa das disciplinas do curso de licenciatura em educação artística com habilitação em música em nota no final do texto. 
por sua vez, a Educação Artística era uma subárea de conhecimento que, juntamente com os cursos de Letras e Educação Física, formava um campo de conhecimento maior, denominado Comunicação e Expressão (PIRES, 2003, p. 83-84).

Dessa forma, a educação artística tornou-se "uma área bastante generosa e sem contornos fixos, flutuando ao sabor das tendências e dos interesses" (Parecer 540/77 apud PIRES, 2003). Uma vez que não era mais tratada como disciplina, segundo o parecer I.707 de 1973, deveria "ser desenvolvida por meio de atividades em Artes Plásticas, em Música, em Teatro e em Artes Cênicas em geral” (Parecer I.707, 1973).

A atual Lei de Diretrizes e Bases da Educação Nacional, lei 9.394, de 1996 (LDBEN/96) mantém a obrigatoriedade do ensino de arte nas escolas da educação básica e os Parâmetros Curriculares Nacionais (PCN/Arte) definem quatro linguagens dentro da área: artes visuais, música, teatro e dança (BRASIL, 1998b). Entretanto, a nova LDBEN/96 não exige a presença de todas elas nos currículos, deixando a cada escola a liberdade de escolha das linguagens artísticas a serem oferecidas (BRASIL, 1996). Ainda de acordo com Pires (2003), a nova legislação revogou a anterior e extinguiu a educação artística, uma vez que foi criada a área de arte.

A Comissão de Especialistas de Ensino (CEE) - Música - determinou, em 1999, as diretrizes curriculares para os cursos de música (HENTSCHKE, 2000 apud PIRES, 2003). Segundo as diretrizes, os cursos podem oferecer habilitações específicas em subáreas de formação de recursos humanos - entre elas está a educação musical. A ESMU/UEMG, diante disso, instituiu o curso de licenciatura em música com habilitação em educação musical escolar - cuja primeira turma ingressou em 2005 - e extinguiu a antiga licenciatura em educação artística com habilitação em música.

\section{A elaboração das monografias: o processo}

A elaboração de monografia de conclusão de curso já vinha sendo obrigatória desde 2004 para os alunos do curso de licenciatura em música com habilitação em instrumento e canto, também oferecido pela Escola de Música da UEMG. Aquele ano foi também o de ingresso da última turma de licenciatura em educação artística. Turma à qual, em 2007, ano de conclusão do curso, foi estendida a obrigatoriedade da produção da monografia de conclusão de curso.

O reconhecimento da importância da pesquisa acadêmica na vida escolar 
de todos os cursos estendeu a realização do Trabalho de Conclusão de Curso, inclusive, aos alunos do bacharelado em instrumento e canto, através da elaboração de um artigo científico com tema referente às áreas de conhecimento abordadas durante o curso.

A ESMU/UEMG estabelece linhas específicas de pesquisa para as monografias de conclusão de curso. Porém, devido ao caráter interdisciplinar da grade curricular da extinta licenciatura em educação artística com habilitação em música, foi facultada aos quinze alunos a opção pelos temas de suas monografias finais de acordo com a área artística de maior afinidade e interesse de cada um.

Essa turma caracterizava-se por uma grande heterogeneidade de personalidades, interesses e formações profissionais. Atores e diretores teatrais, bailarinos, fotógrafos, compositores, arranjadores, flautistas, pianistas, violonistas, chorões, violinistas, percussionistas, webdesigners, professores, regentes e agentes culturais conviveram intensamente durante quatro anos. Entretanto, foi possível observar que toda diversidade, ao longo desse período, amalgamouse e convergiu para um ponto comum: a educação. A consciência de suas funções como educadores responsáveis pela difícil tarefa de levar a arte de volta às escolas brasileiras já permeava a atuação profissional dos alunos.

No entanto, a elaboração de uma monografia passou a representar para essa turma um grande impasse: um pré-requisito importante e indispensável para a conclusão de curso, que demandaria tempo para sua realização e que implicaria no conhecimento de técnicas específicas, praticamente desconhecidas de todos eles até aquele momento. Elaboração de projetos, metodologias de pesquisa, escrita acadêmica, fundamentação teórica, nada disso fazia parte do repertório de conhecimento desses alunos, pois as disciplinas específicas, direcionadas à elaboração de monografias, somente seriam ministradas no decorrer de 2007, ano de suas formaturas.

A liberdade de opção em relação aos temas de seus trabalhos amenizou a aflição inicial dos alunos. Mas como encontrar um foco, uma questão de pesquisa dentro de cada um dos temas escolhidos? No decorrer do primeiro semestre de 2007, os alunos receberam subsídios teóricos para embasarem a elaboração de seus projetos. A disciplina introdução à pesquisa científica abordava as questões formais e filosóficas da elaboração do trabalho científico. Mas o ponto essencial da investigação ainda não estava claro para vários deles.

No segundo semestre, foram programados encontros semanais, que ajudariam os alunos a encontrarem a questão central de suas pesquisas, bem 
como a metodologia mais adequada para a sua realização. Nos encontros, cada um relatava suas questões em relação ao tema escolhido. Nesse relato, a professora e os demais colegas procuravam "filtrar" os pressupostos iniciais, que eram "capturados" na fala espontânea dos alunos. Assim, cada um, a partir de uma fala inicialmente bastante ampla, chegava necessariamente a alguns pressupostos e, posteriormente, ao objetivo geral da pesquisa. A busca de um objetivo geral é extremamente importante, pois, segundo Turato, esse objetivo busca "atingir o que é essencial na pesquisa" (TURATO, 2003, p.558). Portanto, é imprescindível que ele fique completamente esclarecido, a fim de que o aluno entenda exatamente o que vai pesquisar. Segundo esse autor, os pressupostos iniciais levam necessariamente ao objetivo geral e representam "um ponto firme para o início da pesquisa científica” (TURATO, 2003, p.556).

A partir desse objetivo geral, outros encontros foram realizados para que, através do mesmo processo, a professora e os demais colegas conseguissem "filtrar" os objetivos específicos de cada uma das pesquisas. Segundo Turato (2003, p. 558-559), essa categoria de objetivos abarca "as questões afins" que devem ser desenvolvidas. Questões que caracterizam etapas a serem percorridas ao longo da pesquisa e que permitem um detalhamento do objetivo geral (GOLDIM, 2007).

Depois do momento em que os objetivos foram esclarecidos, surgiu uma nova questão. Como realizar essa investigação? Qual o caminho a seguir? Cada um dos alunos, então, procurou verbalizar como imaginava a elaboração de sua pesquisa. A professora, a partir dessa fala, sugeria metodologias que poderiam se adequar à demanda de cada pesquisa. Os alunos, após a leitura de textos específicos sobre metodologia, foram capazes de identificar se as características do caminho escolhido para suas pesquisas eram realmente aquelas descritas por especialistas no assunto, como Laville e Dionne (1999), Turato (2003) e Minayo (2004).

Paralelamente às questões metodológicas, diversas fontes que poderiam servir como fundamentação teórica para as pesquisas foram trazidas para os encontros com os alunos. Os textos que poderiam ser utilizados por vários deles eram lidos e comentados em sala de aula e os mais específicos eram disponibilizados individualmente aos alunos interessados. Vale ressaltar que a busca pelo referencial teórico representou um processo árduo, devido à grande diversidade dos temas. Aos poucos, alguns capítulos começaram a tomar forma. Os alunos passaram a levar seus próprios textos para serem lidos e 
discutidos em sala de aula, o que foi extremamente enriquecedor.

A partir de um certo momento, alguns já haviam coletado dados importantes para suas pesquisas. Iniciou-se, então, outra etapa desse processo: a análise dos dados. Fez-se necessária uma ampla discussão sobre as formas de organização dos mesmos e de sua posterior análise. Nesse momento, a fundamentação teórica entrou novamente em cena para justificar, ou não, os dados encontrados pelos alunos. Em seguida, cada aluno procurou refletir sobre questões que iam além dos resultados da investigação, que transcendiam os resultados encontrados. Assim, as conclusões começaram a se delinear.

\section{A elaboração das monografias: os resultados}

O resultado foi um quadro rico e diverso de conteúdos ligados à música, à educação musical, a outras linguagens de arte (fotografia, dança, teatro) e uma disposição clara da maioria em relacionar tais assuntos à linguagem musical, além de temas ainda pouco discutidos como, por exemplo, novas tecnologias no ensino de música.

Os campos de conhecimento abordados foram muito variados. Por se tratarem de futuros professores, a questão da educação foi a mais instigante e a que rendeu maior número de abordagens, direcionadas para as particularidades de cada aluno e para os problemas que eles enfrentavam no seu cotidiano como estagiários ou já profissionais. Ainda assim, outros campos de conhecimento presentes na estrutura curricular do curso foram ricamente ilustrados.

As ideias de educadores musicais consagrados foram ponto de partida para vários trabalhos. Um dos temas voltados para a educação foi o desenvolvimento da inteligência musical a partir do método Suzuki. A aluna utilizou a Teoria das Inteligências Múltiplas de Howard Gardner (1994) para embasar sua pesquisa de observação de turmas de violino, baseadas no método Suzuki. Outro trabalho apresentado versou sobre a musicalização de idosos: a pesquisa investigou as limitações e possibilidades de musicalização, através da "pesquisa-ação" aplicada a um grupo de mulheres idosas. $O$ modelo $C(L) A(S) P$ (SWANWICK, 1979) e a Teoria Espiral de Desenvolvimento Musical (SWANWICK; TILLMANN, 1986) foram utilizados como ferramenta de avaliação da compreensão musical em dois trabalhos de pesquisa: o primeiro investigou a compreensão musical de bailarinos, o segundo avaliou o canto coral como atividade capaz de promover o desenvolvimento musical. 
Outra abordagem propôs a reflexão sobre a contribuição dada por grandes educadores musicais como Dalcroze (I865-1950), Orff( I895-1982), Willems (I8901978), Koellreutter (1915-2005), Paynter (I93I) e Swanwick (1938) e constatou a combinação das propostas desses autores numa abordagem híbrida, amplamente utilizada atualmente pelos principais professores de música no Brasil. A ciranda praieira, brincadeira popular do litoral de Pernambuco, foi ensinada às crianças do curso de musicalização infantil da Escola de Música da UEMG e resultou numa descrição e análise do processo de vivência da brincadeira.

O uso do computador na educação musical também foi tema de pesquisa, que procurou analisar as particularidades do ensino de música a distância através da internet e desenvolver ferramentas de avaliação eficazes para a qualificação dos alunos. Outro trabalho buscou definir a arte como recurso transformador na educação, promovendo a reflexão sobre as características da sociedade e da educação nos dias atuais e utilizando a arte como elemento de transformação de paradigmas, tendo o professor como parte relevante desse processo.

As políticas públicas municipais de desenvolvimento artístico e musical foram pesquisadas através do projeto Agente Jovem e do grupo Tambolelê, que relacionou a educação musical nas periferias de Belo Horizonte com a mídia e promoveu a utilização de gêneros populares como o axé, o funk e o hip hop como canal de comunicação entre a proposta de educação musical e o público alvo. Numa abordagem específica do ensino do violão, houve também uma proposta de investigação das possibilidades didáticas do repertório de choro na iniciação a esse instrumento.

No campo do teatro, dois trabalhos foram desenvolvidos. Em um deles, o autor buscou estudar a relação do ator com a palavra teatral, investigando na origem do teatro a força comunicativa da palavra, a conexão entre palavra e música e os princípios para que a fala cumpra sua função teatral. Em outro, utilizou-se uma interpretação historicamente fiel do grupo II giardino armonico da obra La notte, de Antonio Vivaldi (I678-I74I) na construção de uma cena teatral.

A música popular também foi importante ponto de partida para outros trabalhos. Foram pesquisadas a função sociológica do compositor popular no cenário da música popular brasileira e a influência dos agentes que compõem o mercado fonográfico e de entretenimento. Em outro trabalho, foi abordado o legado da cantora Elis Regina à música popular brasileira, bem como fatos e meios que levaram a carreira da cantora à consagração. A música erudita se fez presente com a contextualização da vida e obra do compositor austríaco 
Arnold Schoenberg (I874-195I), como também as estruturas ideológicas construídas a partir de sua obra e de sua imagem de compositor revolucionário.

Por fim, a fotografia foi contemplada com um estudo de imagens antigas do bairro Padre Eustáquio, em Belo Horizonte, Minas Gerais, onde está situada a Escola de Música da UEMG. O trabalho demonstrou a importância da fotografia como documento histórico e lançou o alerta da preservação do material fotográfico, que se deteriora com o tempo e se perde para sempre.

\section{Conclusões}

A partir dos resultados apresentados pela última turma do curso de licenciatura em educação artística, fomos levados a refletir sobre uma provável perda de algo precioso devido à extinção desse curso: a riqueza advinda de uma grande heterogeneidade. Os alunos certamente apontaram para a educação do futuro. São artistas e educadores que prenunciaram uma tendência fabulosa definida por Koellreutter (1983) como "a complementaridade da diversidade". As tendências interdisciplinar e transdisciplinar já podem ser sentidas nas mais diversas áreas do conhecimento humano, principalmente nas produções científicas do meio acadêmico como as monografias produzidas por essa turma de alunos.

O que isso significa? Pensando, especificamente, na Universidade do Estado de Minas Gerais como instituição formadora de jovens e produtora de conhecimento. Significa a importância de uma possível integração curricular dos diversos cursos oferecidos pela instituição: licenciatura e bacharelado em música, artes plásticas, artes visuais, design e educação. A especificidade de cada uma dessas áreas de conhecimento seria preservada e aprofundada em suas sedes de origem, mas a possibilidade de convívio direto com as demais disciplinas geraria um conhecimento que, sem dúvida, transcenderia a cada uma delas.

Por entender a importância da interdisciplinaridade no processo educativo como um todo, um primeiro passo já foi dado pela Escola de Música da Universidade do Estado de Minas Gerais, à época da elaboração do projeto pedagógico do novo curso de licenciatura em música com habilitação em educação musical escolar. Ao refletir sobre a heterogeneidade das linguagens artísticas presentes na escola básica, professores responsáveis pelo projeto do novo curso tiveram a preocupação de manter essas linguagens múltiplas de arte em 
forma de oficinas interdisciplinares: cinema, fotografia, expressão corporal, dança, teatro, materiais expressivos, desenho.

Essa experiência tão significativa e viva de interdisciplinaridade na própria instituição universitária reacende a esperança de que experiências semelhantes possam ser levadas por nossos alunos à escola regular. $O$ diálogo entre as linguagens artísticas naquele contexto poderá contribuir para a implementação definitiva da arte como área de conhecimento na educação básica. Além disso, um processo educacional capaz de ampliar o olhar de crianças e jovens certamente representará também uma chance de se resgatar algo precioso que vem sendo perdido pelo homem contemporâneo, tão impregnado pela pressa e pelo consumismo: a capacidade de sentir e de se emocionar. $O$ resgate dessas características tão singulares do ser humano significa a expansão de seu universo perceptivo e o refinamento de sua consciência crítica, condição por si só libertadora.

\section{Notas}

São estas as disciplinas do curso de licenciatura em educação artística da Escola de Música da Universidade do Estado de Minas Gerai, extinto em 2005: Técnica vocal e dicção, Instrumentos alternativos e sua aplicação pedagógica, Regência coral, Instrumento - flauta doce, Instrumento - teclado, Instrumento - violão, História da arte, Estética, Apreciação musical, Folclore brasileiro, Introdução às artes cênicas, Desenho e composição, Modelagem e escultura, Fotografia, Cinema, Materiais expressivos e técnicas de utilização, Fundamentos da arte na educação, História da arte brasileira, Folclore, Psicologia e educação, Didática, Avaliação educacional e teorias pedagógicas, Política educacional e organização da educação básica no Brasil, Prática de ensino, História da educação, Filosofia e educação, Percepção musical, Análise musical, Oficina de coral infantil, Didática da música, Elementos de harmonia, História da música, História da música brasileira, Oficina de criação musical. 


\section{Referências}

BRASIL, Secretaria da Educação Fundamental. Parâmetros Curriculares Nacionais: introdução, $3^{\circ}$ e $4^{\circ}$ ciclos do ensino fundamental. Brasília: MEC/ SEF, 1998a.

. Secretaria da Educação Fundamental. Parâmetros Curriculares Nacionais: arte. Brasília: MEC/SEF, 1998b.

. Lei de Diretrizes e Bases da Educação Nacional, n. 4024, de 20 de dezembro de 196I. Brasília: MEC, 196I.

. Lei de Diretrizes e Bases da Educação Nacional, n. 9394, de 20 de dezembro de 1996. Brasília: MEC, 1996.

. Lei n. 5692, de II de agosto de I97I. Brasília: MEC, I97I.

GARDNER, H. Estruturas da mente. Porto Alegre: Artes Médicas, 1994.

GOLDIM, J. R. Projeto de pesquisa: aspectos éticos e metodológicos.

Disponível em: <http://www.ufrgs.br/bioetica/projeto.htm >. Acesso em: 08 de nov. de 2007.

KOELLREUTTER, H. J. Estética. São Paulo: Novas Metas, 1983.

LAVILLE, C.; DIONNE, J. A construção do saber. Porto Alegre: Artmed, 1999.

MINAYO, M. C. de S. O desafio do conhecimento. São Paulo: Hucitec, 2004.

PIRES, N. A. R. A identidade das licenciaturas na área de música:

multiplicidade e hierarquia. Revista da ABEM, Porto Alegre, v. 9, p.8I-88, set. 2003.

SWANWICK, K.; TILLMAN, J. The sequences of musical development: a study of children's composition. British Journal of Musical Education. Londres, v. 3, n. 3, nov. 1986, p.305-339. 
SWANWICK, K. Music, mind and education. Londres: Routledge, 1988. . A basis for music education. Londres: Routledge, 1979.

TURATO, E. R. Tratado da metodologia da pesquisa clínico-qualitativa. Petrópolis: Vozes, 2003.

UNIVERSIDADE DO ESTADO DE MINAS GERAIS, Projeto pedagógico do curso de licenciatura em educação artística - habilitação em música. Belo Horizonte: 1998.

UNIVERSIDADE DE ESTADO DE MINAS GERAIS, Projeto pedagógico do curso de licenciatura em música - habilitação em educação musical escolar. Belo Horizonte: 2003. 


\section{Art and interdisciplinarity in the Music School of the University of Minas Gerais: an analysis of the students final papers}

\section{Abstract}

The last class of the Art Teacher Education Course with qualification in Music, of the Music School of the University of Minas Gerais - ESMU/UEMG, Brazil, graduated in 2007. The subjects chosen and developed by these students in their final papers were so diverse and rich that called one's attention to the relevance of the interdisciplinary approach of Art Education on college level. The richness involved in the exchanging of ideas was present in the whole process, from the projects to the final results, and turned to be a relevant experience not only for students and teachers but also for the entire Institution. These final papers came to reinforce the significance of heterogeneity as a main characteristic of nowadays education and to show the importance of an interdisciplinary curriculum within university courses, as a tool to deepen specific knowledge without losing the richness produced by diversity.

Keywords: final paper; interdisciplinary approach; education; art teacher; education course. 